\title{
Hepatitis A virus subgenotypes dissemination during a community outbreak in a surrounding region of Rio de Janeiro
}

\author{
Débora Regina Lopes dos Santos/ ${ }^{+}$, Livia Melo Villar ${ }^{1}$, Vanessa Salete de Paula, \\ Gerson Silva de Lima², Ana Maria Coimbra Gaspar
}

Laboratório de Desenvolvimento Tecnológico 'Laboratório de Hepatites Virais, Instituto Oswaldo Cruz-Fiocruz, Av. Brasil 4365, 21040-900 Rio de Janeiro, RJ, Brasil ${ }^{2}$ Departamento de Reativos para Diagnóstico Setor de Bactérias e Recombinantes,

Bio-Manguinhos-Fiocruz, Rio de Janeiro, RJ, Brasil

From December 1999 to December 2001, many cases of hepatitis A were notified in the county of Belford Roxo involving individuals aged 0 to 79 years. Serum samples were collected to evaluate the prevalence of anti-hepatitis $A$ virus (HAV) antibodies, to detect HAV-RNA and to correlate with possible risk factors of HAV infection. Serum samples were screened by commercial IgM and total anti-HAV antibody ELISA and HAV-RNA was isolated and subsequently amplified by reverse transcription-polymerase chain reaction (RT-PCR) at VP1/2A region, sequenced and analyzed. Total anti-HAV prevalence was $87.9 \%$ (203/231) and IgM anti-HAV prevalence was 38.7\% (89/231). Multivariate analysis showed that individuals under 20 years old are risks groups to acquire the infection suggesting that hygienic habits of young subjects are the principal factor of transmission and so they could be the target for vaccine programs. HAV-RNA was amplified from 29 (32.5\%) IgM anti-HAV positive patients and 26 samples were sequenced and classified into subgenotypes IB (8 isolates) and IA (18 isolates). Isolates classified into subgenotype $I B$ were identical representing one distinct strain. We could observe both subgenotypes circulating during the study which suggests different sources of infection. Prophylactic measures as vaccination strategies added to improvements in hygienic and sanitary conditions would be highly effective to reduction of infection.

Key words: hepatitis A virus - molecular epidemiology - co-circulation of subgenotypes IA and IB

Hepatitis A virus (HAV) is an RNA virus that is transmitted mainly by fecal oral route and is the only member of the genus Hepatovirus of the Picornaviridae family (Melnick 1982, 1992). Studies on nucleic acid heterogeneity of HAV strains, in VP1/2A junction, characterize and group isolates in six different genotypes (I-VI) and six sub-genotypes (IA, IB, IIA, IIB, IIIA, and IIIB) (Robertson et al. 1992, Lu et al. 2004). Genotypes are distinguished by $15-25 \%$ sequence diversity, whereas sub-genotypes in each genotype differ in about $7.5 \%$ of base positions (Robertson et al. 1992). Comparison among nucleotide sequences allows genetically relating different strains during an outbreak and providing new insights into the molecular epidemiology of HAV.

HAV is the main cause for acute viral hepatitis which represents a significant public health problem worldwide. However, a progressive decline in hepatitis A mortality rate could be seen in all Brazilian regions, being observed a rate of $0.2 / 100,000$ inhabitants in 1980 to the rate of 0.02/100,000 inhabitants in 2002 (Vitral et al. 1998, 2006). The incidence of hepatitis A in Brazil has markedly decreased as showed by Vitral et al. (1998) who demonstraded that the HAV seroprevalence declined from

Financial support: $\mathrm{CNP}$

+ Corresponding author: santosdl@ioc.fiocruz.br

Received 21 November 2007

Accepted 2 June 2008
98.1 to $7.8 \%$ among children under the age of five in two different populations of low socioeconomic status in Rio de Janeiro, a city located in the Southeastern region (Vitral et al. 1998). This phenomenon can probably be attributed to improvements in sanitary conditions. If this hypothesis is true, then the transmission route of HAV in Brazil may have changed within time. Studying changes in HAV transmission routes in Brazil may therefore elucidate the influence of sanitation on transmission routes. Molecular epidemiological approaches may also be useful for studying transmission routes and provide new information for the control of this disease. Studies carried out in Brazil have shown that two subgenotypes circulate in our country and strains isolated from the same region demonstrated close genetic relatedness (de Paula et al. 2002, 2004, Villar et al. 2004, 2006). In this study, we have analyzed the molecular and epidemiological relationship between HAV isolates recovered from acute cases notified in communities of surrounding region of Rio de Janeiro sampled from 1999 to 2001.

\section{PATIENTS, MATERIALS AND METHODS}

Population study - The county of Belfor Roxo covers $30 \mathrm{Km}$ Northwest of the city of Rio de Janeiro with a population of approximately 435.000 inhabitants. This city is subdivided in five districts (Fig. 1). From December 1999 to December 2001, several cases of acute hepatitis were reported to the epidemiological surveillance of the county of Belford Roxo (ESBRC). All individuals showing clinical signs of hepatitis A (jaundice, fever, dark urine, colure, hepatomegaly abdominal pain) were notified to ESBRC and blood samples were collected. 


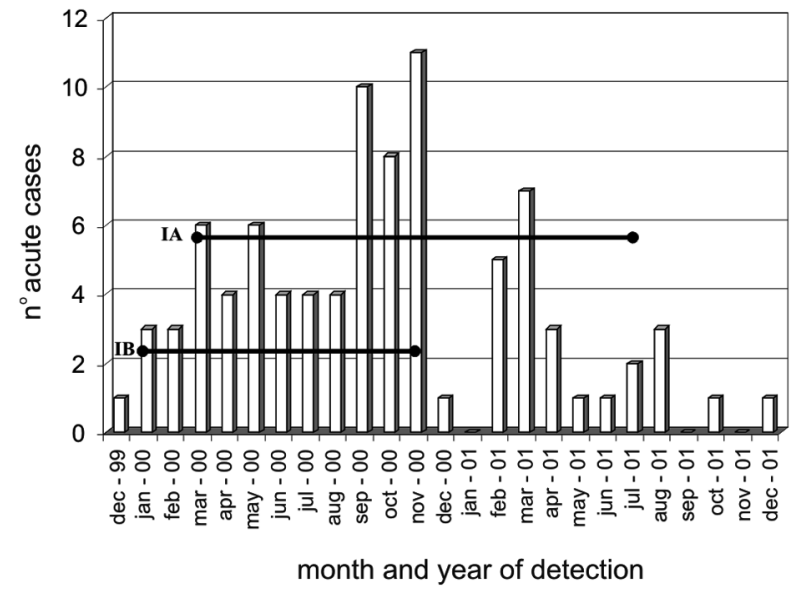

Fig. 1: distribution of hepatitis A IgM anti-HAV cases in the county of Belford Roxo from 1999 to 2001. Bars indicates genotypes from HAV-RNA detected samples obtained during the study.

A total of 231 specimens were collected from suspected cases and household contacts aged 0 to 79 years. Sera samples were processed and stored at $-20^{\circ} \mathrm{C}$ until assays procedures.

Symptomatic and asymptomatic hepatitis A acute cases were defined when the serum sample shown positive test for IgM anti-HAV. As part of the active surveillance program, reported index cases are offered hygienic advice and are questioned about possible risk situations that occurred up to six weeks prior to the first day of illness. Also, susceptible contacts are traced and are subsequently offered hygienic advice.

To investigate the risk factors for the suspect cases, a case control study was performed, choosing as controls the healthy individuals who were negative for IgM antiHAV. Demographic and risk factors analyzed were gender, age group, availability of treated water and sewage system; bath practice in rivers, swimming pools, beaches, lagoons or waterfalls, contact with hepatitis infected suspect and sub-district (I-V). For each exposure factor the odds ratio and $95 \%$ confidence intervals between cases and controls were calculated using the $\chi^{2}$ test with Yates correction. SPSS version 8.0 was used to perform univariate and multivariate analysis. Formal consent to participate in this study was obtained from all subjects.

Serological tests - IgM and total anti-HAV antibodies in sera samples were detected by commercially available ELISA kits (Organon Teknika, Boxtel, The Netherlands) following the instructions of the supplier.

Nucleic acid extraction and reverse transcriptionpolymerase chain reaction (RT-PCR)/Nested RT-PCR Viral nucleic acid was extracted from $100 \mu \mathrm{l}$ of IgM anti-HAV antibody positive sera by TRIzol ${ }^{\circledR}$ method as described by Chomczynski and Sacchi (1987) (Life Technologies, Rockville, MD). RT was carried out using $10 \mu \mathrm{l}$ RNA, 20 pmol of random primers and $200 \mathrm{U}$ of Moloney murine leukemia virus RT (Life Technologies) in a final volume of $20 \mu \mathrm{l}$ at $37^{\circ} \mathrm{C}$ for $1 \mathrm{~h}$, followed by $10 \mathrm{~min}$ incubation at $65^{\circ} \mathrm{C}$. PCR was performed with VP1/2A specific primers described previously (de Paula et al. 2002).
Sequencing and phylogenetic analysis - The nested RT-PCR products were purified using the QIAquick Gel extraction kit (Qiagen, GmbH, Germany) according to the manufacturer. Direct nucleotide sequencing reaction was performed in both directions with a Big Dye Terminator kit (Applied Biosystems, CA, USA) and an automatic DNA sequencer (ABI Prism 310; Applied Biosystems). To construct a phylogenetic tree, sequences from 168 nucleotides (position 3024 to 3191 ) of VP1/2A junction were aligned using the Clustal X program (Thompson et al. 1997). Afterwards, a matrix was generated for the Kimura-two parameter model (Kimura 1990), and using this matrix and the Neighbor Joining model, a phylogenetic tree was created and her reliability was assessed by bootstrap resampling (1000 pseudo-replicas). These methods were implemented with software from the MEGA program (Kumar et al. 1994). Twenty HAV strains isolated from different regions of the world and isolated from other outbreaks occurred in Rio de Janeiro were included in this dendogram: HAP108 (DQ198361, Brazil), RJ215 (AY323023, Brazil), RJPMC1 (AF410386, Brazil), childA07 (DQ061171, Brazil), childB02 (DQ061160, Brazil), RDJBrasilPA (L07681, Brazil), RJ104 (AY323022, Brazil), RJ12 (AY323034, Brazil), HAS15 (X15464, USA), childD12 (DQ061182, Brazil), RJ055 (AF410384, Brazil), RJNSG2 (AF410383), childA26 (DQ061185, Brazil), HAP279 (DQ198362, Brazil), HAP331 (DQ198360, Brazil), staff006 (DQ061178, Brazil), HM175Australia (M14707, Australia), RJ049 (AY322851, Brazil), RJ005 (AF410381, Brazil), SLF88 (L07729, Sierra Leoa), Nor21 (AF050227, Norway), CF53 (AY644676, France), HAJNG0690F (AB258387, Japan). Sequences obtained in this study are available in Genbank under access numbers DQ438954-DQ438970; EF222210-EF222220.

\section{RESULTS}

Descriptive epidemiology - Between December 1999 and December 2001, 231 serum specimens were collected from 138 suspected HAV cases and 93 household contacts living in a surrounding region of Rio de Janeiro. They were distributed in five districts: I - 19\%; II - 22.1\%; III - $12.1 \%$; IV - 4.8\%; V - 39.8\%. Fig. 1 show the time of onset for all acute patients over the two years. The peak of cases was in November 2000 when 11 cases were determined. The population study comprised 120 females and 111 males aging 0 to 79 years $($ mean $=22.08)$. Total antiHAV prevalence was $87.9 \%(203 / 231)$ and IgM anti-HAV prevalence was $38.7 \%$ (89/231). IgM anti-HAV detection decreased in individuals aging more than 20 years demonstrating statistical significance $(p<0.00)$ (Table), IgM positive individuals were most detected in males $(56.2 \%)$ but it was not statistically significant. Furthermore, IgM anti-HAV was most prevalent in individuals living in district V (42.7\%) (Fig. 2).

Among 89 hepatitis A acute cases, 32 (40.5\%) reported having contact with hepatitis infected suspect, $26(36.6 \%)$ do not have treated water, $47(61.8 \%)$ do not have sewage system availability, 23 (30.3\%) related bath practice in rivers, swimming pools, beaches, lagoons or waterfalls during the 2-6 weeks before symptoms onset. 
TABLE

IgM anti-hepatitis A virus (HAV) antibodies from acute hepatitis A cases in the country of Belford Roxo during 1999 - 2001

\begin{tabular}{lcccc}
\hline Variables & $\begin{array}{c}\text { Positive } \\
\mathrm{n}(\%)\end{array}$ & $\begin{array}{c}\text { Total } \\
\mathrm{n}(\%)\end{array}$ & $\begin{array}{c}\text { Univariate } \\
\text { analysis (p) }\end{array}$ & $\begin{array}{c}\text { Multivariate } \\
\text { analysis }(\mathrm{p})\end{array}$ \\
\hline $\begin{array}{c}\text { Age } \\
\leq 20\end{array}$ & $79(88.8)$ & $137(60.1)$ & 0.00 & 0.00 \\
$>20$ & $10(11.2)$ & $91(39.9)$ & & \\
Sex & & & 0.05 & \\
Male & $50(56.2)$ & $111(48.1)$ & & \\
Female & $39(43.8)$ & $120(51.9)$ & & \\
Use of treated water & & 0.92 & \\
Yes & $45(63.4)$ & $107(62.9)$ & & \\
No & $26(36.6)$ & $63(37.1)$ & & \\
Sewage facilities & & 0.76 & \\
Yes & $47(61.8)$ & $113(63.1)$ & & \\
No & $29(38.2)$ & $66(36.9)$ & & \\
River or sea swimming & & 0.003 & \\
Yes & 23(30.3) & $35(19.9)$ & & \\
No & $53(69.7)$ & $141(80.1)$ & & \\
Contact with suspect cases & & \\
Yes & $32(40.5)$ & $79(42.9)$ & & \\
No & $47(59.5)$ & $105(57.1)$
\end{tabular}

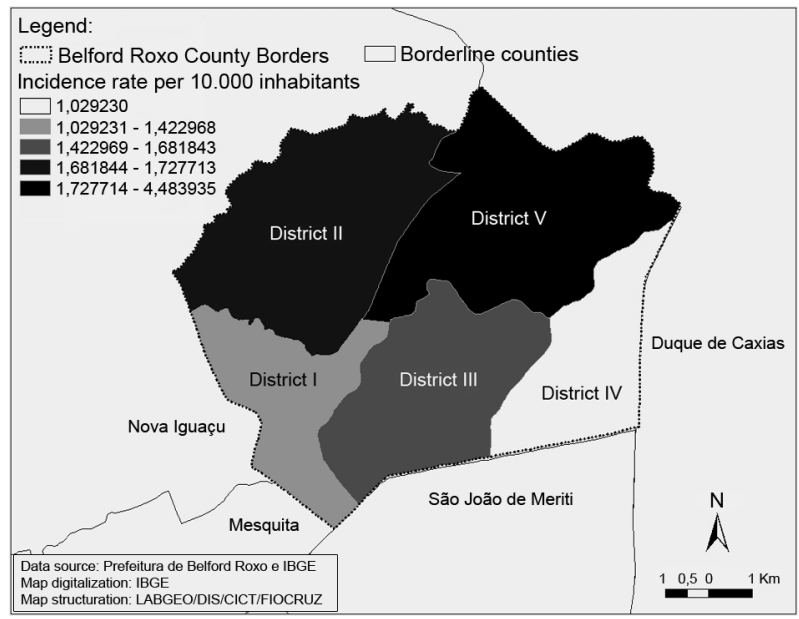

Fig. 2: map of the county of Belford Roxo classified into sub-districts and IgM anti-HAV incidence according to districts of Belford Roxo (I-V).

Univariate analysis demonstrated that age and bath practices were statistically correlated with hepatitis A infection, while in multivariate analysis only age was statistical significant showing that subjects under 20 years old have more risk to acquire hepatitis A (Table).

HAV-RNA detection - HAV-RNA was amplified from $29(32.5 \%)$ IgM anti-HAV positive patients. Among HAV-RNA positive patients, 28 aged less than 20 years old, 15 were contact from index patients, 15 lived at district $\mathrm{V}$, and 18 were males. HAV-RNA detection was not associated with demographic or risk-factor variables (data not shown).

Phylogenetic relatedness of HAV isolates - A phylogenetic analysis was carried out to determine the genetic variability degree among 26 the county of Belford Roxo
HAV isolates compared to other 22 prototype HAV strains and isolates from state of Rio de Janeiro. All isolates from acute cases notified in the county of Belford Roxo were classified in genotype I, most of them (18/26) belonged to subgenotype IA and the other eight isolates were genotype IB (Fig. 2). Identity among nucleotide sequence of IA isolates varied from $84.9 \%$ to $95 \%$ and between IB isolates $100 \%$ similarity was observed defining a single strain. A comparison of the predicted amino acid sequences of the VP1/2A region from the county of Belford Roxo isolates demonstrated an identity from 86.1 to $100 \%$ (data not shown).

Co-circulation of both subgenotypes (IA and IB) were observed during January to November 2000. Both subgenotype were detected in all subdistricts except for subdistrict IV in which subgenotype IB was not detected.

\section{DISCUSSION}

This study addressed a community-wide outbreak of hepatitis A in terms of serological and genetic spectrum focusing on demographic and risk factor information as also characterizing isolates sequences among individuals.

Total anti-HAV prevalence in this population was $87.8 \%$ as it was demonstrated by other researchers in areas where hepatitis A is endemic (de Almeida et al. 2002, Jacobsen \& Koopman 2004, Venugopalan et al. 2004). Recent studies have demonstrated a decrease to intermediate and low HAV prevalence in some regions of Brazil due to improvements in hygienic conditions (Vitral et al. 1998, 2006, Clemens et al. 2000, de Almeida et al. 2002, Zago-Gomes et al. 2005). The existence of areas of intermediate endemicity for HAV infection similar to observed in this study may lead to outbreaks as it was described in recent years in Rio de Janeiro (Villar et al. 2002, de Paula et al. 2003, Morais et al. 2006), so vaccination strategy should be revised.

In our study, $64 \%$ of acute HAV cases were under 20 years old showing that this group represents a higher risk group to acquire HAV infection. Furthermore the risk of acquiring infection in univariate analysis was associated to younger subjects (less than 20 years old) and bath practices showing that person to person transmission and water could be important vehicles of transmission. It is known that water represents an important vehicle (Garin et al. 1994, Villar et al. 2002) and wide-community outbreaks linked to water consumption have been documented (De Serres et al. 2002, Venugopalan et al. 2004). Most of acute HAV cases in this study do not have sewage system $(61.8 \%)$ which can be one of the factors involved in HAV transmission since the presence of HAV has been detected in this specimen by molecular approaches (Villar et al. 2007). Nevertheless, person to person transmission is also an important mode of transmission responsible for several outbreaks (Robertson et al. 2000, de Paula et al. 2002, Villar et al. 2002) and since the multivariate analysis showed age group as the only risk factor, we could suggest that hygienic habits of younger subjects are the main factor of transmission.

In the county of Belford Roxo, $26 \mathrm{HAV}$ isolates had a 168 bp fragment of VP1/2A junction sequenced and most of them (61.5\%) belonged to subgenotype IA 


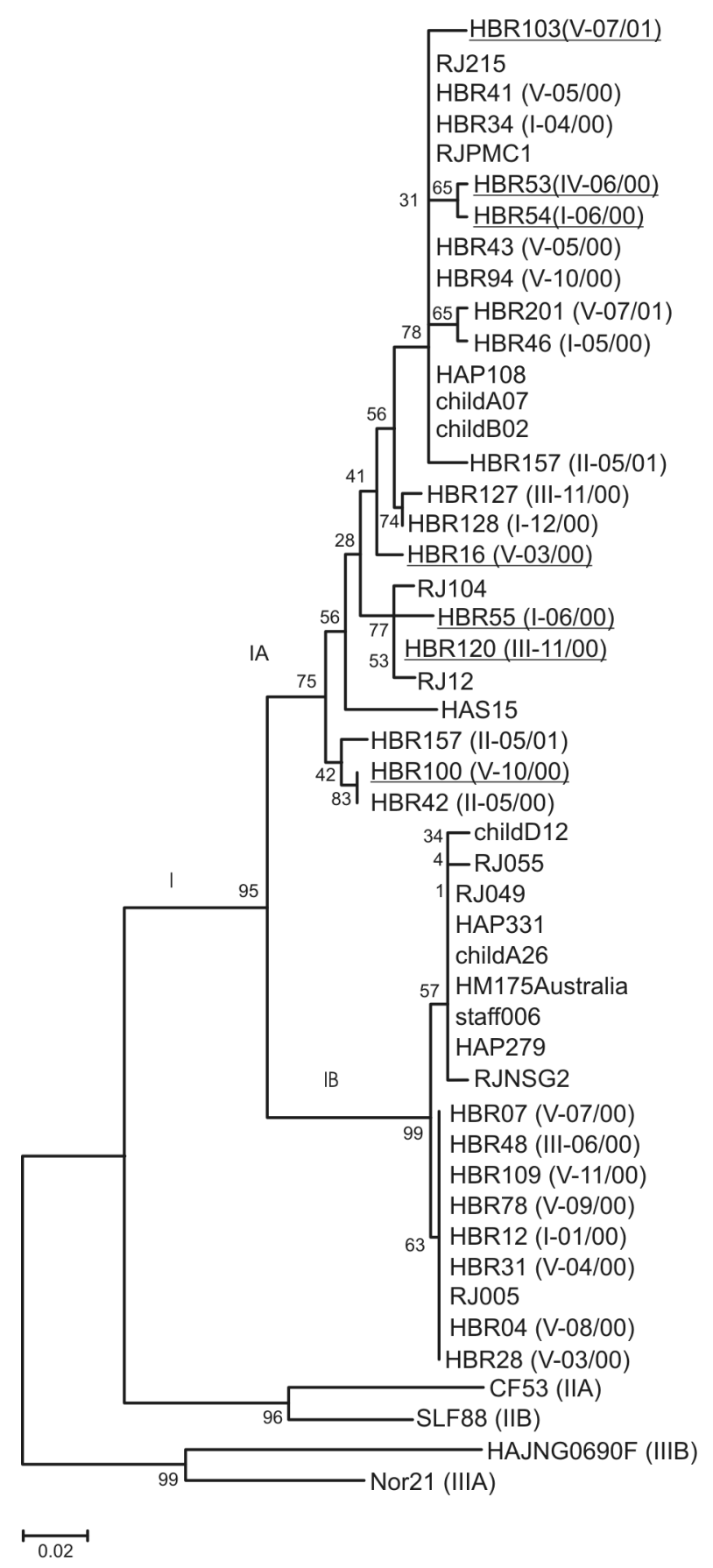

Fig. 3: phylogenetic analysis of 168 bp of VP1-2A junction of HAV genome. Genotypes and subgenotypes are indicated at nodes. Bars indicate genetic distances. The isolates identified during the outbreak occurred in 2000 and 2001 in the county of Belford Roxo are shown in bold and are initiated in HBR. Index cases are underlined. In parentheses, are shown subdistrict followed by month and year of notification.

that comprises over $80 \%$ of strains isolated worldwide (Robertson et al. 1992). It was observed a considerable variability degree among isolates of genotype IA as Costa-Mattioli et al. (2001) demonstrated among IA strains isolated during an outbreak occurred in France (CostaMattioli et al. 2001). We also observed eight isolates from subgenotype IB in this community with $100 \%$ of similarity among each other and to a strain isolated from a sporadic case in Rio de Janeiro (de Paula et al. 2002). Isolates from subgenotype IA and subgenotype IB were closely related to other strains isolated from sporadic cases (de Paula et al. 2002), and outbreak cases that occurred in an orphanage in Rio de Janeiro (de Paula et al. 2003, Morais et al. 2006) and another one that occurred in a public school in the county of Paracambi (Rio de Janeiro) (Villar et al. 2002). In the county of Belford Roxo, subgenotype IB was detected from January 2000 till November 2000 and all isolates shared the same homology suggesting a common source of infection. Subgenotype IA isolates co-circulated with subgenotype IB isolates during march 2000 to November 2000 suggesting that at least two sources of infection were responsible for HAV infection during this period. Co-circulation was previously reported among sporadic cases and outbreaks in Rio de Janeiro (de Paula et al. 2002, 2004, Villar et al. 2004, Morais et al. 2006).

This result demonstrates the endemic circulation of some strains in Rio de Janeiro and concomitant circulation of HAV strains at least from two different sources during this outbreak. Epidemiological results demonstrated that age was an independent factor associated to HAV infection and we conclude that person to person transmission associated to the absence of sewage system could be important vehicle of transmission.

The association of epidemiological, geographic and molecular data provides information that helps to determine potential contamination sources of HAV infection (Normann et al. 1995, Robertson et al. 2000) and could facilitate the adoption of preventive measures such as vaccine strategies, information about prevention of HAV infection and adoption of hygienic measures, such as sodium hypochlorite distribution. These two last measures were adopted in this county on 2001 and reduced the incidence of HAV infection in this community but vaccination should also be considered especially in individuals aging less than 20 years old to avoid HAV dissemination.

\section{ACKNOWLEDGEMENTS}

To employees of ESBRC for technical assistance and data provided.

\section{REFERENCES}

Chomczynski P, Sacchi N 1987. Single-step method of RNA isolation by acid guanidinium thiocyanate-phenol-chloroform extraction. Anal Biochem 162: 156-159.

Clemens SA, da Fonseca JC, Azevedo T, Cavalcanti A, Silveira TR, Castilho MC, Clemens R 2000. Hepatitis A and hepatitis B seroprevalence in 4 centers in Brazil. Rev Soc Bras Med Trop 33: 1-10.

Costa-Mattioli M, Ferre V, Monpoeho S, Garcia L, Colina R, Billaudel S, Veja I, Perez-Bercoff R, Cristina J 2001. Genetic variability of hepatitis A virus in South America reveals heterogeneity and cocirculation during epidemic outbreaks. J Gen Virol 82: 2647-2652.

de Almeida LM, Amaku M, Azevedo RS, Cairncross S, Massad E 2002. The intensity of transmission of hepatitis A and heterogeneities in socio-environmental risk factors in Rio de Janeiro, Brazil. Trans R Soc Trop Med Hyg 96: 605-610.

de Paula VS, Baptista ML, Lampe E, Niel C, Gaspar AM 2002. Characterization of hepatitis $\mathrm{A}$ virus isolates from subgenotypes IA and IB in Rio de Janeiro, Brazil. J Med Virol 66: 22-27. 
de Paula VS, Lu L, Niel C, Gaspar AM, Robertson BH 2004. Genetic analysis of hepatitis A virus isolates from Brazil. J Med Virol 73: 378-383.

de Paula VS, Saback FL, Gaspar AM, Niel C 2003. Mixed infection of a child care provider with hepatitis A virus isolates from subgenotypes IA and IB revealed by heteroduplex mobility assay. $J$ Virol Methods 107: 223-228.

De Serres G, Duval B, Shadmani R, Boulianne N, Pohani G, Naus M, Fradet MD, Rochette L, Ward BJ, Kain KC 2002. Ineffectiveness of the current strategy to prevent hepatitis A in travelers. $J$ Travel Med 9: 10-16.

Garin D, Fuchs F, Crance JM, Rouby Y, Chapalain JC, Lamarque D, Gounot AM, Aymard M 1994. Exposure to enteroviruses and hepatitis A virus among divers in environmental waters in France, first biological and serological survey of a controlled cohort. Epidemiol Infect 113: 541-549.

Jacobsen KH, Koopman JS 2004. Declining hepatitis A seroprevalence: a global review and analysis. Epidemiol Infect 132: 1005-1022.

Kimura DK 1990. Testing nonlinear regression parameters under heteroscedastic, normally distributed errors. Biometrics 46: 697-708.

Kumar S, Tamura K, Nei M 1994. MEGA: molecular evolutionary genetics analysis software for microcomputers. Comput Appl Biosci 10: 189-191.

Lu L, Ching KZ, de Paula VS, Nakano T, Siegl G, Weitz M, Robertson BH 2004. Characterization of the complete genomic sequence of genotype II hepatitis A virus (CF53/Berne isolate). $J$ Gen Virol 85: 2943-2952.

Melnick JL 1982. Classification of hepatitis A virus as enterovirus type 72 and of hepatitis B virus as hepadnavirus type 1. Intervirology 18: 105-106.

Melnick JL 1992. Properties and classification of hepatitis A virus. Vaccine 10: S24-26.

Morais LM, de Paula VS, Arantes MR, Oliveira ML, Gaspar AM 2006. Early infection and asymptomatic spread of hepatitis A virus in a public child care center in Rio de Janeiro, Brazil: should attending children under two years of age be vaccinated? Mem Inst Oswaldo Cruz 101: 401-405.

Normann A, Pfisterer-Hunt M, Schade S, Graff J, Chaves RL, Crovari P, Icardi G, Flehmig B 1995. Molecular epidemiology of an outbreak of hepatitis A in Italy. J Med Virol 47: 467-471.

Robertson BH, Averhoff F, Cromeans TL, Han X, Khoprasert B,
Nainan OV, Rosenberg J, Paikolf L, Debess E, Shapiro CN, Margolis HS 2000. Genetic relatedness of hepatitis A virus isolates during a community-wide outbreak. J Med Virol 62: 144-150.

Robertson BH, Jansen RW, Khanna B, Totsuka A, Nainan OV, Siegl G, Widell A, Margolis HS, Isomura S, Ito K, Ishizu T, Moritsugu Y, Lemon SM 1992. Genetic relatedness of hepatitis A virus strains recovered from different geographical regions. $J$ Gen Virol 73: 1365-1377.

Thompson JD, Gibson TJ, Plewniak F, Jeanmougin F, Higgins DG 1997. The CLUSTAL_X windows interface: flexible strategies for multiple sequence alignment aided by quality analysis tools. Nucleic Acids Res 25: 4876-4882.

Venugopalan B, Nik Rubiah NA, Meftahuddin T, Ayu M, Prema R, Ruhaini I, Murugan S 2004. Hepatitis A outbreak in Hulu Langat district, Selangor state, Malaysia during April-October 2002. Med J Malaysia 59: 670-673.

Villar LM, de Paula VS, Diniz-Mendes L, Guimarães FR, Ferreira FF, Shubo TC, Miagostovich MP, Lampe E, Gaspar AM 2007. Molecular detection of hepatitis A virus in urban sewage in Rio de Janeiro, Brazil. Lett Appl Microbiol 45: 168-173.

Villar LM, Esteves da Costa MC, de Paula VS, Gaspar AM 2002. Hepatitis a outbreak in a public school in Rio de Janeiro, Brazil. Mem Inst Oswaldo Cruz 97: 301-305.

Villar LM, Lampe E, Meyer A, Gaspar AM 2004. Genetic variability of hepatitis A virus isolates in Rio de Janeiro: implications for the vaccination of school children. Braz J Med Biol Res 37: 1779-1787.

Villar LM, Morais LM, Aloise R, Melo MM, Calado IA, Lampe E, Gaspar AM 2006. Co-circulation of genotypes IA and IB of hepatitis A virus in Northeast Brazil. Braz J Med Biol Res 39: 873-881.

Vitral CL, Gaspar AM, Souto FJ 2006. Epidemiological pattern and mortality rates for hepatitis A in Brazil, 1980-2002- a review. Mem Inst Oswaldo Cruz 101: 119-127.

Vitral CL, Yoshida CF, Lemos ER, Teixeira CS, Gaspar AM 1998. Age-specific prevalence of antibodies to hepatitis A in children and adolescents from Rio de Janeiro, Brazil, 1978 and 1995. Relationship of prevalence to environmental factors. Mem Inst Oswaldo Cruz 93: 1-5.

Zago-Gomes MP, Stantolin GC, Perazzio S, Aikawa KH, Goncalves CS, Pereira FE 2005. Prevalence of anti-hepatits A antibodies in children of different socioeconomic conditions in Vila Velha, ES. Rev Soc Bras Med Trop 38: 285-289. 